\title{
Performing a Large-Scale Modal Test on the B2 Stand Crane at NASA's Stennis Space Center
}

\author{
Eric C. Stasiunas, Russel A. Parks, Brendan D. Sontag \\ NASA Marshall Space Flight Center \\ Huntsville, AL
}

\begin{abstract}
A modal test of NASA's Space Launch System (SLS) Core Stage is scheduled to occur at the Stennis Space Center B2 test stand. A derrick crane with a 150-ft long boom, located at the top of the stand, will be used to suspend the Core Stage in order to achieve defined boundary conditions. During this suspended modal test, it is expected that dynamic coupling will occur between the crane and the Core Stage. Therefore, a separate modal test was performed on the B2 crane itself, in order to evaluate the varying dynamic characteristics and correlate math models of the crane. Performing a modal test on such a massive structure was challenging and required creative test setup and procedures, including implementing both AC and DC accelerometers, and performing both classical hammer and operational modal analysis. This paper describes the logistics required to perform this large-scale test, as well as details of the test setup, the modal test methods used, and an overview and application of the results.
\end{abstract}

